\title{
A resolução/administração dos conflitos e o reconhecimento do Terceiro: um debate necessário ${ }^{1}$
}

\author{
Conflicts resolution/administration and rec- \\ ognition of Third party: a necessary debate
}

Fabiana Marion Spengler ${ }^{2}$

Resumo: O presente texto tem como tema o papel desenvolvido pelo "Terceiro" na resolução/administração dos conflitos. O principal problema de pesquisa a ser respondido é: de que modo o papel do Terceiro

1 O presente texto foi produzido a partir da pesquisa desenvolvida no projeto: “O terceiro e o conflito: o mediador, o conciliador, o juiz, o árbitro e seus papéis políticos e sociais" coordenado pela autora e financiado pela Fundação de Amparo a Pesquisa do Estado do Rio Grande do Sul - Fapergs, Edital 02/2017 - PqG - Pesquisador Gaúcho.

2 Bolsista de Produtividade em Pesquisa do CNPq (Pq2). Pós-doutora em Direito pela Università degli Studi di Roma Tre, em Roma, na Itália, com bolsa CNPq (PDE). Doutora em Direito pelo programa de Pós-Graduação stricto sensu da Universidade do Vale do Rio dos Sinos - UNISINOS - RS, com bolsa Capes, mestre em Desenvolvimento Regional, com concentração na área Político Institucional da Universidade de Santa Cruz do Sul UNISC - RS, docente dos cursos de Graduação e Pós Graduação lato e stricto sensu da UNISC, Coordenadora do Grupo de Pesquisa "Políticas Públicas no Tratamento dos Conflitos" vinculado ao CNPq; coordenadora e mediadora do projeto de extensão: "A crise da jurisdição e a cultura da paz: a mediação como meio democrático, autônomo e consensuado de tratar conflitos" financiado pela Universidade de Santa Cruz do Sul - UNISC; autora de diversos livros e artigos científicos, e-mail: fabiana@unisc.br 
vem sendo desempenhado na sociedade hodierna? Quais são as pessoas, os grupos, organizações, entidades e instituições estatais e não estatais que desenvolvem o papel de Terceiro atualmente? Para responder à tal indagação, o texto procura primeiramente analisar o modo como o papel do Terceiro vem sendo desempenhado na sociedade atual. Posteriormente buscou-se delimitar os diferentes grupos de força (organizações, entidades e instituições estatais e não estatais) que contribuem para o equilíbrio e para a regulamentação interna do Estado e que desenvolvem o papel de Terceiros. Para cumprir com o proposto, o método de abordagem utilizado foi o dedutivo. Como método de procedimento foi utilizado o método monográfico, e como técnica de pesquisa aplicou-se a bibliográfica. As principais conclusões as quais o texto chegou - confirmando a hipótese formulada - é de que atualmente existem terceiros incluídos e excluídos que conforme esse seu status participam de situações polêmicas e/ou agonais. Esses Terceiros podem ser pessoas, grupos, entidades instituições estatais ou não, e cumprem seu papel resolvendo e/ou administrando conflitos.

Palavras-chave: conflito, papel do terceiro, Estado.

Abstract: The present article has as its subject-matter the role of a third party in conflict administration and resolution. The main question to be answered in this research is: How third party has been developing its role in modern society? Who are the responsible in people, groups, organizations, entities, governmental and non-governmental institutions for developing this third party function nowadays? To have this questions responded, this article had the scope to firstly analyze how third party play its role in modern times and secondly how to delimitate different "groups of force" (organizations, entities, governmental and 
non-governmental institutions) which contribute to balance, to making laws and developing this third party role in conflict solution internally in the states. In order to reach an accurate result, the author used a deductive reasoning approach, a monographic method of procedure and a bibliographic technique of researching. The main conclusions found - confirming this formulate hypothesis - is that currently exist "included and excluded third parties" which participate in polemic and/or agonal situations. These named third parties can be the same people, groups, entities, governmental and non-governmental institutions that comply with their role in resolving and administrating conflicts.

Keywords: conflict, role of third party, State.

\section{Introdução}

O conflito é inevitável e salutar. Sua importância sociológica e política pode ser avistada na organização, manutenção e transformação das relações sociais. Essa constatação é senso comum. Sendo o conflito inerente aos indivíduos e aos grupos sociais, ele deixa de ser um evento patológico para se tornar um elemento fisiológico da estrutura relacional humana. Porém, existem circunstâncias nas quais o conflito precisa de uma intervenção externa aos grupos ou aos indivíduos conflitantes. Tal intervenção acontece, na maioria das vezes, para evitar um desfecho complexo e difícil (como uma discussão) ou trágico (como a explosão de uma luta armada). Essa intervenção é atribuída a uma Terceira parte, composta por um indivíduo ou grupo cujo papel é de triangularizar a relação rompendo com a polaridade instituída e possibilitando aproximação e comunicação. 
O papel a ser desempenhado por esse Terceiro tem importância no modo como a resolução/administração do conflito será encaminhada. Para dimensionar a atuação do Terceiro, é preciso verificar o tipo de conflito, quem são os conflitantes e qual é o papel político/sociológico a ser por ele desempenhado.

Por conseguinte, o presente texto tem como tema o papel do Terceiro - sob a ótica da política e da sociologia - e sua importância para o tratamento (gestão e administração) de conflitos. O principal problema de pesquisa a ser respondido é: de que modo o papel do Terceiro vem sendo desempenhado na sociedade hodierna? Quais são os grupos, organizações, entidades e instituições estatais e não estatais que desenvolvem o papel de Terceiro político/sociológico atualmente ${ }^{3}$ ?

A pesquisa teve como objetivo geral analisar o modo como o papel do Terceiro vem sendo desempenhado na sociedade atual. Como objetivo específico, buscou-se delimitar os diferentes grupos de força (organizações, entidades e instituições estatais e não estatais) que contribuem para o equilíbrio e para a regulamentação interna do Estado e que desenvolvem o papel de Terceiros. ${ }^{4}$

Nesses termos, o primeiro item abordou as teorias quanto a figura do Terceiro, respondendo quem ele é e que papel espera-se que desempenhe. A análise aconteceu par-

3 Especula-se que o Terceiro pode ser traduzido em organizações econômicas ou sindicais, de partidos políticos, de organizações religiosas ou intelectuais, de um grupo de interesses ou simplesmente na figura do juiz, do conciliador, do árbitro e do mediador e esse é também um dos pontos de investigação do texto.

4 SPENGLER, Fabiana Marion. O pluriverso conflitivo e seus reflexos na formação consensuada do Estado. Revista direitos fundamentais $\mathcal{E}$ democracia, 22, 3: p.189-209. 2017b. Disponível em http://revistaeletronicardfd.unibrasil. com.br/index.php/rdfd/issue/view/301982-0496, consultado em 20/11/19. Revista Direitos Fundamentais e Democracia. 1982-0496. 
tindo da definição de terceiro incluído e excluído na situação polêmica e na situação agonal. Adiante, o Terceiro ausente foi objeto de investigação bem como aqueles definidos como aliado, neutro e o mediador de paz. O papel desenvolvido pelos terceiros político/sociológico internos ao Estado, aqui consideradas as organizações, entidades, instituições estatais e não estatais foram objeto de análise no último item.

Para fins de cumprir com o proposto, o método de abordagem utilizado foi o dedutivo, partindo da relação entre argumentos gerais, denominados premissas, para argumentos particulares, até se chegar a uma conclusão. Como método de procedimento foi utilizado o método monográfico e como técnica de pesquisa aplicou-se a bibliográfica baseada em documentação indireta que serviu de base teórica para o desenvolvimento dos objetivos e das principais conclusões.

Esse é, pois, o texto que agora se apresenta.

\subsection{Afinal, quem é o Terceiro 5 ?}

É possível demonstrar a importância do Terceiro ${ }^{6}$ nas relações políticas e sociais. Se uma comunidade estivesse dividida unicamente em dois campos opostos sem nenhum intermediário, a situação se tornaria explosiva e rapidamente se transformaria em conflito. Existindo já o conflito, seus limites fugiriam ao controle e a situação se agravaria. Desse modo, o Terceiro é um fator capital para a "concórdia" interior, tanto na forma de associações como de instituições das quais participam os cidadãos de opiniões, valores, crenças, preceitos morais e éticos e de partidos contrários.

5 Sobre o assunto sugere-se a leitura de SPENGLER, Fabiana Marion. Chi è dunque il Terzo? Riflessioni su società e conflitto. Firenze: Classi, 2019.

6 Considerando a etimologia e o significado da palavra "terceiro" na língua portuguesa, tem-se que é: 
Por conseguinte, o relativo consenso indispensável às mudanças sociais tem por fundamento o Terceiro, cujo papel não consiste somente em ser um tampão que amorteça os choques, os antagonismos e as tensões, senão também servir de intermediário para a comunicação entre os que pretendem ignorar-se ou dirigirem-se, agressivamente, uns contra os outros. Em uma sociedade que não reconhece o Terceiro o conflito se torna permanente ou um dos campos submeteria o outro ao seu jugo a ponto de absorvê-lo, o que produziria uma fusão totalitária como na maior parte das ditaduras revolucionárias modernas.

Enfim, o Terceiro é a configuração elementar da sociedade pois condiciona o equilíbrio, possibilita as combinações sociais mais diversas, e ao mesmo tempo é um fator de remissão dos conflitos internos. É notório que as sociedades totalitárias que não reconhecem o Terceiro se confundem na torpeza de uma unanimidade letárgica, devido à falta de

\footnotetext{
"Num. Ordinal de três; aquele que em ordem se segue ao segundo: terceiro filho. Qualificativo da pessoa gramatical de quem se fala. Terceiro Mundo, conjunto de países pouco desenvolvidos economicamente, que não pertencem nem ao grupo dos Estados industrializados de economia liberal, nem ao grupo dos de tipo socialista. Terceira via, terceira cópia de um documento original. Religião católica Ordem Terceira, associação de fiéis que, embora vivendo no mundo, se filiam a uma ordem religiosa. S.m. Estranho, ou simplesmente uma terceira pessoa: mostrar-se discreto na presença de terceiros. Medianeiro, intercessor: recorreu à influência de terceiro junto ao ministro. Lógica Princípio da exclusão do terceiro, princípio que enuncia: "de duas proposições contraditórias, se uma é verdadeira, a outra é fatalmente falsa" (não existe outra possibilidade). S.m.pl. Outras pessoas. Direito. Pessoas ou entidades que, não sendo parte direta numa causa ou processo, podem ter interesses ligados aos que ali estão em jogo". (http://www.dicio.com.br/terceiro/ acesso em 20.11.2019). De todas as diversas e possíveis definições de Terceiro apresentadas apenas a última: "pessoas ou entidades que, não sendo parte direta numa causa ou processo, podem ter interesses ligados aos que ali estão em jogo" importa ao desenvolvimento da presente pesquisa. Ao ler a palavra Terceiro, pois, é a esse conceito que o leitor deve se reportar.
} 
canais de comunicação e de criatividade crítica que inspira. O Terceiro é a condição de estabilidade das sociedades livres, porque somente é possível a aparição de uma maioria e de uma minoria em consequência de uma oposição política. ${ }^{7}$

Por outro lado, conforme Eugène Enriquez ${ }^{8}$, o Terceiro é o "reconhecimento da falha, da existência humana". Isso significa que uma vez:

Excluído o terceiro, surge a possibilidade da relação dual pura, a união mística, a comunhão perfeita. $O$ chefe passa então a ter domínio total sobre suas tropas, que se identificam com ele. ${ }^{9}$

Assim, ao definir o Terceiro, normalmente se fala de uma relação entre duas pessoas ou grupos que estão em conflito ou então cujos interesses poderão ser conflitivos. Nessas situações é necessário ter a presença de alguém (o Terceiro) que possa restabelecer o acordo, que se ocupe do negócio ou da relação jurídica (ou dos direitos que foram ou que estão prestes a serem violados $)^{10}$. O papel desempenhado por essa figura, independentemente de qual é exatamente sua posição (imparcial ou aliado), terá influência no desenvolvimento e desfecho do conflito ${ }^{11}$.

7 FREUND, Julien. Sociología del conflicto. Traducción de Juan Guerrero Roiz de la Parra. Madrid, Ministerio de Defensa, Secretaría General Técnica. D. L. 1995a.

8 ENRIQUEZ, Eugène. As figuras do poder. São Paulo,Via Lettera. 2007.

9 ENRIQUEZ, 2007, p.79.

10 PORTINARO, Píer Paolo. Il terzo. Una figura del Politico. Milano, Fraco Angeli. 1986.

11 Ainda que o papel desempenhado pelo Terceiro seja muito importante e necessário para que o equilíbrio social exista e se mantenha, encontramse obstáculos para a definição dessa figura o que comprova o "velho paradoxo do conceito de 'terceiro' que, se existe e não é simplesmente aliado ou inimigo, existe sempre ou como tertius gaudens, ou como tertius miserabilis" (RESTA, 2005a, p. 32). 
Analisando-se os conflitos penais processualizados cabe a interrogação de Antoine Garapon ${ }^{12}$ :

Porque se organiza sempre o processo, no Ocidente, em torno de três papéis? Porque não conceber a justiça como um frente a frente entre o acusado, assistido pelo seu defensor, e o juiz?

O autor vai além ao afirmar que:

Se o processo se limitasse a uma confrontação opondo o juiz ao acusado, o juiz deixaria de ser árbitro, passando a ser parte. É esta a diferença entre a relação política e a relação judicial, sempre mediada por uma terceira parte desinteressada. ${ }^{13}$

Observa-se, então, a necessidade absoluta dessa figura que, sendo (na estrutura judicial especificamente) "imparcial e desinteressado" triangularizará a relação e permitirá a administração do conflito de modo formal, burocrático e racional.

A necessidade de reconhecer o Terceiro permitiu a observação dos conceitos de relação diádica e de relação triádica. Conforme escreveu Simmel ${ }^{14}$, existem relações entre indivíduos e entre grupos que são sociologicamente chamadas de diádicas e outras de triádicas. Em apertada síntese, as primeiras são aquelas que dizem respeito às relações que envolvem duas pessoas ou grupos sem a intermediação de uma terceira parte; por outro lado, as últimas comportam e reconhecem a figura do Terceiro.

Para Simmel ${ }^{15}$ o número de atores é uma variável significativa, que implica na compreensão dos contornos de uma relação diádica e/ ou triádica. As relações triádicas dão vida

12 GARAPON, Antoine; Bem Julgar: ensaio sobre o ritual judiciário. Lisboa: Instituto Piaget, 1997.

13 Ibidem, p. 101-102.

14 SIMMEL, Georg. Soziologie. 5 ed, Berlim, Duncker \& Humblot. 1968.

15 Ibidem. 
a uma fenomenologia social original quanto as características e relações entre dois indivíduos ou entre uma pluralidade de elementos não reduzíveis a uma estrutura tripartida. A dualidade pode significar sínteses e unificações mas também antíteses e separações. Assim, “a chegada do Terceiro significa transições, reconciliações, superações de oposição absoluta - mas, ocasionalmente, também a sua criação."16

Interpretando Simmel ${ }^{17}$, tem-se que a diferença entre os dois tipos de relação se manifesta, todavia, no fato de que a associação ou dissociação dos dois elementos de uma dupla é qualquer coisa de imediato, espontâneo e originário, enquanto a unificação ou cisão interna de uma relação triádica é sempre algo mediato, artificial e derivado, posto que nesse caso os dois elementos são vistos como juntos ou separados também devido a presença ou a intervenção do Terceiro. ${ }^{18}$

Considerando tais afirmativas e interpretando-as, especialmente diante da necessidade de tratar conflitos jurídicos, tem-se que, primeiramente, antes de ser judicializado, o conflito é de caráter diádico e pode, imediatamente e de modo espontâneo, causar associação ou dissociação. A ausência do Terceiro pode significar maiores dificuldades de lidar com esse conflito de modo adequado, assim como pode ser traduzida por uma harmonização devido ao encontro de uma resposta consensual para o problema ${ }^{19}$. Por outro lado, a presença do Terceiro na relação triádica gera a hipótese de uma harmonização (junção) ou de uma dificuldade na

16 Ibidem, p. 90-101.

17 Ibidem, 1968.

18 PORTINARO, 1986.

19 SPENGLER, Fabiana Marion. O pluriverso conflitivo e seus reflexos na formação consensuada do Estado. Revista direitos fundamentais \& democracia, 22, 3: p.189-209. Disponível em http://revistaeletronicardfd.unibrasil.com.br/ index.php/rdfd/issue/view/301982-0496, consultado em 20/11/19. Revista direitos fundamentais e democracia. 1982-0496. 2017b. 
gestão do conflito (separação), que será mediata e artificial. O Terceiro, assim, auxilia os envolvidos a lidarem com seus problemas, mas não necessariamente o resultado será a reconstrução da relação. Essa última alternativa dependerá, muitas vezes, da habilidade desse Terceiro em auxiliar no diálogo e nas escolhas dos conflitantes. Nesses contextos, é possível ter, exemplificativamente, o Terceiro Juiz, que lida com o conflito mas não se preocupa, necessariamente, com a autonomia, a espontaneidade e a reconstrução da relação, e o Terceiro Mediador, que busca tais objetivos.

Assim, o Terceiro pode trabalhar na tentativa de composição do conflito, como aquele que fomenta um "compromisso" (mediador) ou como o árbitro de uma "pacificação jurídica" (juiz), na qual um dos conflitantes pode sair vitorioso em detrimento do outro.

Em termos sociológicos, na concepção de Portinaro ${ }^{20}$, Simmel abandonou - o que se percebe a partir de suas conclusões - o clássico modelo de Marx (1996) e Dahrendorf $(1992)^{21}$. As concessões diádicas do conflito, seja na variante marxista ou na liberal, são caracterizadas por alguns postulados de fundo, que as pesquisas empíricas acabaram por revelar inconsistentes ou reduzidas. Tais concessões pressu-

\section{PORTINARO, 1986.}

21 Segundo Ruth A. Wallace e Alison Wolf, a teoria do conflito pode ser dividida em duas possibilidades distintas: “Un primo gruppo di teorici ritiene che lo scienziato sociale abbia l'obbligo morale di impegnarsi in una critica alla società. Rifiuta di separare - o di ammettere che si possa realmente separare - l'analisi dal giudizio, il fatto dal valore. I teorici di questo gruppo sono generalmente convinti che possa esistere, in linea di principio, una società nella quale non ci sia più posto per il conflitto sociale. Per questo vengono frequentemente considerate utopisti. Il secondo gruppo di teorici considerare, al contrario, il conflitto come un aspetto inevitabile e permanente nella vita sociale e respinge l'idea che le conclusioni a cui giunge la scienza sociale siano necessariamente giudizi di valore. I fautori di tale sono anzi impegnati a fondare una scienza sociale che rispetti gli stessi canoni di obiettività che formano le scienze naturali. 
põem: a) a unidimensionalidade do conflito, ou seja, a hipótese de reduzi-lo a um fator específico (os meios de produção ou o poder) dentro de uma esfera específica (a economia ou a política); b) a bipolaridade do conflito, o seu atrelamento a dinâmica das ações e reações de somente dois conflitantes principais; c) a homogeneidade das partes, verificadas na sua coesão e unidade interna; d) por fim, ao caráter de competitividade do conflito e na sua perfeita redução a um jogo de soma zero ${ }^{22}$.

...gli appartenenti al primo gruppo, che comprende il marxismo moderno, $\mathrm{i}$ teorici della Scuola di Francoforte e C. Wright Mills, si rifanno ampiamente al lavoro di Karl Marx. Nel secondo gruppo, che raccoglie i contributi di Ralph Dahrendorf, Lewis Coser e Randall Collins, l'influenza di Marx è ancora evidente, ma la continuità più rilevanti sono quelle con gli scritti di Max Weber" (WALLACE e WOLF, 2001, p. 83).

22 A teoria dos jogos consiste em uma argumentação ad infinitum, que só viria a ser parcialmente solucionada por John F. Nash, na década de 1950, por meio do conceito de Equilibrium. A história deu a John von Neumann o título de pai da teoria dos jogos, por ter ele sido o primeiro a sistematizar e a formular com profundidade os principais arcabouços teóricos sobre os quais a teoria foi construída. Embora tenha publicado trabalhos desde 1928 sobre a teoria, apenas em 1944 sua obra maior, Theoryof Games and Economic Behavior, escrita em conjunto com Oskar Morgenstern, foi publicada. Neste livro, demonstrou-se que problemas típicos do comportamento econômico podem ser analisados como jogos de estratégia. Além disso, nesta obra também foram formulados diversos conceitos básicos da teoria dos jogos e para a própria economia, tais como a noção de utilidade, de jogos de soma zero e de soma não-zero e jogos de duas ou mais pessoas, além do conceito de minimax (ALMEIDA, 2003, p. 177). Jogos de soma zero e de soma não-zero: Jogos de soma zero são aqueles em que há dois jogadores cujos interesses são totalmente opostos (NASAR, 2002, p. 106). Estes jogos são aqueles nos quais o ganho de um jogador significa sempre a derrota do outro: não pode haver, por exemplo, em um jogo de xadrez, a vitória por parte dos dois lados. Uma característica importante destes jogos é que eles são, necessariamente, jogos não-cooperativos: um jogador não agregará valor algum de utilidade se cooperar com o outro. Jogos de soma não-zero, representam a maior parte dos conflitos reais, motivo pelo qual o estudo dos jogos de soma zero teriam pouca importância para as ciências sociais. (ALMEIDA, 2003, p. 186). 
Já Simmel ${ }^{23}$, conforme Portinaro ${ }^{24}$, trabalha as similitudes e diferenças das relações diádicas e triádicas com uma concepção diversa, exposta em três postulados metodológicos: a) o primeiro sugere estudar o conflito sem abstraí-lo do complexo contexto social no qual se desenvolve; $b$ ) o segundo põe em evidência seu caráter multidimensional; c) o último ressalta sua ambivalência funcional.

Seguindo tais postulados percebe-se que dentro do pluriverso político e social o conflito produz um realinhamento e, por consequência, uma simplificação, mas não restabelece naturalmente a existência dos Terceiros e a sua capacidade de interação. A pluridimensionalidade do conflito comporta, por outro lado, a possibilidade da sua clivagem com o ingresso na arena competitiva dos Terceiros atores, interessados em manter o controle sobre determinados aspectos das apostas - e talvez somente sobre aqueles.

Modernamente, a Sociologia trabalha com a lógica de que conflitos diádicos são exceção e que normalmente a presença do Terceiro ${ }^{25}$ acontece. Assim sendo, o reconhecimento dos conflitos triádicos sugere o abandono de velhos mitos dualísticos, expressos, na opinião de Portinaro ${ }^{26}$, "pela dualidade servo/senhor, proletário/burguesia, amigo/ inimigo". Desse modo, permanece visível que, na realidade social, "prevalecem relações multipolarizadas e em particular relações triádicas elásticas ou institucionalizadas." ${ }^{27}$

Investigando similitudes e diferenciações entre os conflitos diádicos e triádicos é importante referir a postura

\section{SIMMEL, 1968.}

24 PORTINARO, 1986.

25 Importante referir que esse Terceiro pode ser representado em pessoas físicas ou jurídicas, tais como ONGs e instituições públicas, dentre outras.

26 PORTINARO, 1986, p.54.

27 Ibidem, p.58. 
evidenciada por Freund ao resumir afirmando: a) o conflito diádico existe quando se pressupõe o dualismo amigo/inimigo, ou seja, a bipolaridade, a dissolução, o desaparecimento da figura do Terceiro; nestes termos, o conflito se define como uma relação social marcada pelo Terceiro excluído; b) triádica é a dinâmica conflitiva quando o ambiente no qual se desenrola o conflito e a sua superação contam com a presença de um Terceiro.

Conclui-se, então, que, para instituir o modo pelo qual se trata o conflito e qual é a relação (diádica/triádica) existente entre os conflitantes, é condição necessária que o papel do Terceiro seja desenvolvido efetivamente e não se confunda com a função desempenhada pelos próprios conflitantes ou com qualquer outro ator coadjuvante. Porém, a percepção do modo como os protagonistas (conflitantes e Terceiro) e os demais atores coadjuvantes atuam na administração do conflito significa uma cisão e uma diferenciação teórica entre o estado polêmico e o estado agonal, cujo assunto será debatido a seguir.

\subsection{O Terceiro in/excluído no estado agonal e no estado polêmico}

Conforme o já visto anteriormente, a relação constituída pelo código binário amigo $\mathrm{X}$ inimigo dissolve a figura do Terceiro. Diante dessa afirmativa o conflito pode ser definido como a relação social marcada pela exclusão do Terceiro. Porém, para compreender a construção do tecido social é preciso observar que ele é uma relação entre participantes que podem estar associados a uma unidade coesa, como um grupo, ou então estar dispersos no contexto social. Desse modo, não se pode ignorar a importância do papel desempenhado pelo Terceiro que, mesmo excluído no momento inicial para fins de permitir/identificar o desenrolar do 
conflito, ganha papel de destaque no desenlace do mesmo com importância significativa no modo e no resultado de seu tratamento quando incluído na relação.

A diferença entre a postura do Terceiro e o papel por ele desempenhado, se de inclusão ou exclusão, gera a identificação da existência ou não da figura do Estado no contexto conflitivo. Detentor no monopólio da violência legítima, o Estado trata o conflito em uma relação de inclusão do Terceiro, reflexo de situações agonais em contraposição ao estado polêmico, no qual o Terceiro encontra-se excluído. ${ }^{28}$

Assim, na situação agonal, verifica-se que o Estado toma para si o monopólio da violência legítima, alçando-se no direito de decidir litígios e chamando a possibilidade de aplacar a violência através de um sistema diverso do religioso e do sacrificial ${ }^{29}$, denominado Sistema Judiciário ${ }^{30}$. Esse último se diferencia dos primeiros porque não é ao culpado que se voltam os olhos, mas à vítima não vingada, sendo preciso dar a ela uma satisfação meticulosamente calculada, que apagará os seus desejos de vingança sem acendê-los novamente. Não se trata de legislar a propósito do bem ou do mal, não se trata de fazer respeitar uma justiça abstrata, trata-se de preservar a segurança do grupo afastando a vingança, de preferência com uma reconciliação baseada na composição ou em qualquer outra que resulte possível mediante um encontro predisposto, de modo tal que a violência não volte

\section{FREUND, 1995a.}

29 Sobre o assunto, é de grande importância a obra de Renè Girard, na qual ele demonstra como o sacrifício possibilitava o distanciamento da violência, interpretando-o como violência substitutiva, reconhecendo em seu âmago uma verdadeira operação de transferência coletiva que se efetua às expensas da vítima e que investe as tensões internas, os rancores, a rivalidade, todas as agressões no seio da comunidade (GIRARD, 2005).

30 Sobre o tema sugere-se a leitura de MACHADO, Igor Suzano. A decisão judicial entre a hermenêutica moral e a articulação política Revista Brasileira de Estudos Políticos . Belo Horizonte, n. 109, pp. 365-409, jul./dez. 2014. 
a ocorrer. Tal encontro se desenvolverá em campo fechado, de forma regulada, entre adversários bem determinados. ${ }^{31}$

Para que se entenda melhor esse processo, é importante distinguir entre situação polêmica e situação agonal. A primeira é refletida na violência aberta e direta. É uma situação conflitiva ou que corre o risco de chegar a sê-lo, pouco importando o grau de agressividade. A característica essencial da situação polêmica é o enfrentamento de opositores como inimigos, o que quer dizer que se dão, mutuamente, o direito de se suprimir fisicamente.

A situação polêmica pode ser transitória ou não. Quaisquer que sejam seus traços, cruéis ou mais moderados, e qualquer que seja a violência que possa suscitar, o conflito está no centro da situação polêmica. No fundo, a situação polêmica pressupõe conflitos francos e diretamente qualificáveis, assim como as provocações e intimidações que podem desencadeá-lo segundo a evolução das circunstâncias que ocorram. Na situação polêmica o Terceiro está excluído, permitindo o desenvolvimento do conflito de modo natural.

Já a situação agonal é aquela em que logrou desativar os conflitos e substitui-los por outra forma de rivalidade, conhecida pelo nome de competição, de competência ou de concurso ${ }^{32}$. Nesses termos, se assimila-se a um jogo. A característica essencial é de que os rivais não se comportam como inimigos, e sim como adversários ${ }^{33}$, o que quer dizer

31 GIRARD, René. La violenza e il sacro. Traduzione di Ottavio Fatica e Eva Czerkl. Milano, Adelphi. 2005.

32 Sobre o modo como o estado agonal pode influenciar e ser influenciado pelos debates sociais, dentre eles aqueles que falam de democracia, sugerese a leitura de MOUFFE (2005), Por um modelo agonístico de democracia.

33 Giovanni Cosi diferencia adversário de inimigo salientando: L'avversario è infatti colui senza il quale, nel conflitto, io non esisto: solo dove lui è, anch'io posso veramente essere. Con lui ci si confronta. L'avversario mi permette infatti non solo di misurarmi con lui, ma anche con me stesso: $\mathrm{mi}$ fa scoprire i miei limiti le mie possibilità. L'avversario è come me: ha i miei 
que de antemão a violência e a intenção hostil estão excluídas, ainda que permaneça a possibilidade de vencer ou de cair frente ao outro competidor. ${ }^{34}$

Na situação agonal o Terceiro (o melhor exemplo é o juiz/magistrado) encontra-se incluído e os meios de jogar são definidos de antemão, sendo que ambos os competidores renunciam ao ataque da integridade física recíproca. Os meios de definir as regras circulam desde o estabelecimento de instituições até a criação do Direito. Tais regras servem para impor condutas e proibições aos rivais, bem como determinar as condições de vitória.

Em resumo, a situação agonal é fundadora de uma ordem reconhecida por todos, que não está na vontade discricionária do vencedor, como ocorre ao acabar um conflito violento. No entanto, a estabilidade da situação agonal é precária, podendo sofrer abalos. Na tentativa de manter a ordem a qualquer custo, muitas vezes se lança mão do uso abusivo da coerção, fazendo da mesma um instrumento de opressão.

Nestes termos, a situação agonal objetiva a submissão da vida à regulamentação e ao Direito ${ }^{35}$. É também conhecida como o "estado dos juízes", pois busca no procedimento judicial a solução de rivalidades e de divergências políticas. Assim, o direito realiza a função de dirimir os conflitos de

stessi timore e le mie stesse speranze; imparando a conoscerlo, scoprendo la sua forza e le sue ragioni, i suoi punti deboli e le sue incongruenze, imparo a conoscere anche i miei. Perciò gli devo rispetto. Il nemico è invece colui che mi impedisce di esistere: dove lui è, io non posso essere. Con lui si combatte; fino alla resa, o all'annientamento (COSI, 2004. n. 9. p. 23).

34 FREUND, 1995a.

35 Il dominio, la repressione dei conflitti con la forza o con la minaccia del ricorso alla forza, è un grande male politico che ogni cittadino dovrebbe sentire come tale, anche se non condivide la posizione di altri cittadini che riconoscono a esso una particolare priorità rispetto ai grandi mali (HAMPSHIRE, 2000. p. 64). 
duas maneiras: "com uma ação preventiva e com uma ação posterior, ou seja, tentando impedir que eles surjam ou então lhes pondo termo no caso de já terem surgido". As normas primárias estão geralmente voltadas para a prevenção; as normas secundárias estão geralmente voltadas para a repressão. ${ }^{36}$

Contudo, as dúvidas nascem da incerteza de que a criação que regulamenta os conflitos por parte do direito e a instauração da situação agonal seja sempre desejável, temendo que ela possa determinar um conservadorismo social ao impor regras de flexibilidade e plasticidade rígidas que não atendam à complexidade da sociedade na qual estão inseridas. ${ }^{37}$

No momento em que o Sistema Judiciário (ou situação agonal, como quer Freund) passa a reinar absoluto como único meio de impor regras de tratamento de conflitos, dissimula - e ao mesmo tempo revela - a mesma vingança avistada nos sacrifícios religiosos, diferenciando-se somente pelo fato de que a vingança judicial não será seguida de outra, rompendo, assim, a cadeia vingativa ${ }^{38}$.

Desse modo também é possível diferenciar situação polêmica de agonal informando que a primeira pode ser exemplificada no estado de natureza que é um estado de guerra uma vez que sem direito, no qual as leis positivas ainda não existem e as leis naturais existem, mas não são

36 BOBBIO, Norberto. O Terceiro Ausente: Ensaios e Discursos sobre a Paz e a Guerra.Tradução de Daniela Versiani. Barueri, Manole. 2009.

37 HAMPSHIRE, Stuart. Non c'è giustizia senza conflitto. Democrazia come confronto di idee. Traduzione di Giovanna Bettini. Milano, Feltrinelli. 2000.

38 Por isso, segundo Eligio Resta, é confiado ao mecanismo judiciário não o exercício da virtude, mas a difícil tarefa de dizer a última palavra sobre os conflitos e, graças a isso, minimizar a violência, evitando o seu perpetuar. Depurada da retórica mais ou menos justificada, esta é a função que o sistema legal atribui ao juiz: interromper o conflito e decidir (RESTA, 2005a, p. 38). 
eficazes; já a situação agonal pode ser ilustrada, conforme Bobbio $^{39}$, como o Estado civil no qual os homens, por meio de um acordo de cada um deles com todos os outros, instituem um sistema de leis válidas e eficazes para o objetivo de cessar a guerra de todos contra todos, instaurando a paz. Trata-se, portanto, de um "estado pacífico exatamente porque é um estado jurídico, e a passagem de um estado ao outro ocorre por um ato jurídico que é o contrato" 40 . Portanto, "enquanto o estado de natureza é um estado de guerra causado pela ausência de direito, o Estado civil é um estado de paz porque é consequência de um ato jurídico." 41

O Poder Judiciário é parte do Estado que nasceu do contrato social e que racionaliza a vingança, a subdivide e limita como melhor lhe parece e a manipula sem perigo, buscando uma técnica eficaz de prevenção da violência. Essa racionalização da vingança se apoia sobre a independência da autoridade judiciária que recebeu tal encargo, atribuição que ninguém discute. Assim, o Judiciário não depende de ninguém em particular, é um serviço de todos e todos se inclinam diante de suas decisões. ${ }^{42}$

Somente ao Poder Judiciário se atribui o direito de punir a violência porque ele possui sobre ela um monopólio absoluto. Graças a esse monopólio, consegue sufocar a vingança, assim como exasperá-la, estendê-la, multiplicá-la. Nesses termos, o sistema sacrifical e o Judiciário possuem a mesma função, porém o segundo se mostra mais eficaz, desde que associado a um poder político forte. Todavia, ao delegar a tarefa de tratamento dos conflitos ao Poder Judiciário - num perfeito modelo hobbesiano de transferência de

39 BOBBIO, 2009.

40 Ibidem, p.160.

41 BOBBIO, 2009, p.160.

42 GIRARD, 2005. 
direitos e de prerrogativas - o cidadão ganha, de um lado, a tranquilidade de deter a vingança e a violência privada/ ilegítima para se submeter à vingança e à violência legítima / estatal, mas perde, por outro, a possibilidade de tratar seus conflitos de modo mais autônomo e não violento, através de outras estratégias (como a mediação, por exemplo). ${ }^{43}$

Por conseguinte, a sociedade atual permanece inerte enquanto suas contendas são decididas pelo juiz, Terceiro incluído da situação agonal ${ }^{44}$. Da mesma forma, como o cidadão de outrora esperava pelo Leviatã para que ele fizesse a guerra em busca da paz, resolvesse os litígios e trouxesse segurança ao encerrar a luta de todos contra todos, atualmente verifica-se que o tratamento e a regulação dos litígios são transferidos ao Judiciário, esquecidos de que o conflito é um mecanismo complexo que deriva da multiplicidade dos fatores, que nem sempre estão definidos na sua regulamentação; portanto, não se trata só de normatividade e decisão. ${ }^{45}$

Unidos pelo conflito, os litigantes esperam pelo Terceiro (juiz) que o "solucione". Espera-se pelo Judiciário para que diga quem tem mais direitos, mais razão ou quem é o vencedor da contenda. Trata-se de uma transferência de prerrogativas quanto à gestão do conflito se direciona ao Terceiro juiz que, na situação agonal, o traduz na linguagem

43 SPENGLER, Fabiana Marion. Da jurisdição à mediação: por uma outra cultura no tratamento dos conflitos. 2 ed, Ijuí, Unijuí. 2016a.

44 La nostra cultura appartiene da tempo al gruppo di quelle che hanno deciso di delegare prevalentemente al diritto statale e ai suoi strumenti formali di decisione delle controversie la gestione dei conflitti sociali. Non importa se di civil o di common law, se accusatori o inquisitori, i nostri sistemi giuridici ci sembrano i soli capaci di garantire un livello accettabile di ordine e sicurezza, scongiurando al tempo stesso la necessità di ricorrere a interventi di controllo eccessivamente repressivi, se non addirittura totalitari (COSI, 2004, p. 21).

45 RESTA, Elígio. Il diritto Fraterno. Roma-Bari, Laterza. 2005a. 
dele ${ }^{46}$. Desse modo, partindo do processo de racionalização weberiana, o Estado, ao deter a forma de poder legal, detém, também, o monopólio legítimo da decisão vinculante. Assim, as atenções continuam centradas na figura do juiz, do qual se espera a última palavra, "não importa qual, mas a última". O lugar do juiz entre os conflitantes é uma questão complicada, uma vez que ele não se deixa encerrar na fácil fórmula da lei que assegura "distância de segurança" das razões de um e do outro. Ele vive no conflito e do conflito que ele decide, pronunciando a última palavra. ${ }^{47}$

Entretanto, um Sistema Judiciário chamado a decidir sobre tudo e com poderes muitas vezes discricionários e pouco controláveis é o lugar que oculta quotas fortes de irresponsabilidade: consente álibis e cobre a aguda diferença entre aquilo que o sistema da jurisdição diz que é e o que faz, e aquilo que na realidade é e faz. ${ }^{48}$

Assim, observa-se uma oferta monopolista de justiça de um sistema identificado como agonal, com a inclusão de um Terceiro que decide, incorporada ao sistema da jurisdição, delegado a receber e a regular uma conflitualidade crescente. Atualmente, chamamos essa conflitualidade crescente de explosão da litigiosidade, que tem muitas causas, mas que nunca foi analisada de forma mais profunda. Mas, o que acontece quando o Terceiro não está (in)excluído? Quando

46 Isso se dá, segundo Maurice Blanchot, porque o juiz tem o direito de ser único maître du language. A expressão maître du language é decisiva e densa, como só podia ser aquela de um pensador como Maurice Blanchot, que trabalhou de maneira muito convincente sobre o poder da escrita e sobre a ideia de comunidade. A conexão entre linguagem e comunidade não é, obviamente, imprevista, mas encontra ligações e mediações através do juiz abre caminhos insuspeitos por meio dos quais se descobre que a linguagem da comunidade não corresponde nunca à comunidade de linguagem (BLANCHOT, 1996).

47 RESTA, 2005a.

48 RESTA, 2005a. 
ele não é encontrado? Quando ele se faz ausente? Sobre o debate é o item a seguir.

\subsection{O Terceiro ausente}

Segundo Bobbio ${ }^{49}$, "um sistema político duradouro e estavelmente pacífico é um sistema político no qual ocorreu a passagem do terceiro entre as partes para o terceiro acima das partes". Essa passagem já ocorreu dentro da maioria dos estados nos quais é possível encontrar - em termos jurídicos - a figura do Terceiro identificada no juiz, por exemplo. Porém, quanto ao sistema internacional a passagem ainda não ocorreu ou ocorreu de forma ainda imperfeita.

Tal se dá porque, não obstante ter sido criada uma autoridade central, como a Organização das Nações Unidas (ONU), por exemplo, dotada de poder para arbitrar todos os conflitos, não se deu a essa instância poder de coerção para obrigar os conflitantes a cumprir as decisões que lhe são atinentes ou os pactos dos quais participaram. Como consequência, segundo Portinaro ${ }^{50}$ "poucas são as situações de crise ou de conflito nas quais a ONU pode participar de modo eficaz na prevenção ou na neutralização de guerras civis ou de conflitos internacionais".

Isso acontece, segundo o mesmo autor, devido à falta de um exército da ONU com poder de coerção para fins de fazer cumprir os acordos entabulados. Desse modo, falta coerção, poder de mando, para que esse Terceiro seja considerado "supra" partes, como é o caso do Judiciário nas relações conflitivas intraestatais ${ }^{51}$.

49 BOBBIO, 2009, p. LIII-LIV.

50 PORTINARO,1986, p. 300.

51 Sobre o assunto é interessante a leitura de EINSTEIN e FREUD (2005) Um diálogo entre Freud e Einstein: por que a guerra? e WERMUTH (2015). Porque a guerra? De Einstein e Freud à atualidade. 
Com o desenvolvimento do Estado, o tratamento dos conflitos passou a ser objeto da autoridade judiciária e essa passagem da situação polêmica para a situação agonal intraestatal ocorreu porque "para ser eficaz em dirimir os conflitos entre as partes, o Terceiro deve dispor de um poder superior ao delas" ${ }^{\prime 52}$. Nesse caso, dentro de cada Estado identificamos figuras de Terceiros. Porém, Bobbio salienta que ao mesmo tempo:

Um Terceiro superior às partes que seja eficaz sem ser opressivo deve dispor de um poder democrático, ou seja, fundado sobre o consenso e sobre o controle das mesmas partes das quais deve dirimir os conflitos. Em outras palavras, não deve ser despótico. ${ }^{53}$.

Em termos intraestatais, o governante da nação deve ser democrático. Isso significa que o futuro da paz $^{54}$ encontra-se diretamente conectado com o futuro da democracia ${ }^{55}$. E a democracia, por sua vez, assim pactuada efetivamente pressupõe a existência de um Terceiro e de um estado agonal no qual a luta livre desigual se transformou em combate regulamentado.

O estado/situação agonal, entendido como aquele no qual o conflito está regulamentado possui, como função, aquela de dirimir os conflitos. Tradicionalmente, a administração/resolução dos conflitos é considerada um dos objetivos do Estado, especialmente atribuído ao Judiciário. Segundo Bobbio esse objetivo é compreendido como "Zwangsordnung (ordenamento coativo), ou então como

52 BOBBIO, 2009, p.LIII-LIV.

53 Ibidem, p.LIII-LIV.

54 "Entendida a paz como aquela que 'não tem a guerra como alternativa', para utilizar a feliz expressão de Umberto Campagnolo, que se tornou o lema da Sociedade Européia de Cultura, de cuja atividade, voltada a unir os homens de cultura acima das fronteiras, e no que se refere à Europa ao abater idealmente o muro de Berlim, participei assiduamente desde o fim da guerra até hoje". (BOBBIO, 2009, p. LIV)

55 "Entendida a democracia como a forma de governo que se funda sobre: 
ordenamento que se serve do uso legítimo da força para realizar os seus fins." 56

Nesses termos, o poder judicial, por meio dos veredictos acompanhados de sanções que podem consistir em atos de coerção física, tais como retirar a vida, a liberdade ou a propriedade, manifesta esse ponto de vista transcendente às perspectivas particulares que é a visão soberana do Estado, detentor do monopólio da violência simbólica legítima. ${ }^{57}$

Para que a situação/estado agonal se consolide é preciso considerar três condições:

a primeira:

É um pacto de não agressão que consiste no compromisso recíproco por parte dos contraentes, que podem ser indivíduos, grupos, nações, em excluir o uso da violência nas suas relações recíprocas. $[\ldots]^{58}$

b) a segunda condição é um pacto em termos mais elevados, consistente não mais em um não fazer ("de agora em diante não nos agrediremos mais"), mas sim em um fazer: "um pacto com base no qual os próprios contraentes entram em acordo para estabelecer regras gerais para a solução pacífica dos conflitos futuros. ${ }^{\prime 59}$

1.Um pacto preliminar e negativo de não agressão entre as partes que pretendem constituir entre si uma associação permanente.

2.Um segundo pacto positivo no qual as partes decidem estabelecer regras para a solução das controvérsias futuras, sem que seja necessário recorrer ao uso da força recíproca.

3.A sujeição a um poder comum tão forte a ponto de ser capaz de fazer respeitar os dois pactos precedentes.

4.O reconhecimento e a efetiva proteção de alguns direitos de liberdade, civil e política, que impeçam o poder assim constituído de se tornar despótico". (BOBBIO, 2009, p. LIV)

56 BOBBIO, 2009, p. 160.

57 BOURDIEU, Pierre. O Poder Simbólico. Tradução de Fernando Tomaz (português de Portugal). 9 ed, Rio de Janeiro, Bertrand Brasil. 2006.

58 BOBBIO, op. cit., p. 246.

59 Ibidem, p. 246-247. 
c) a terceira condição nasce da consideração de que os dois pactos, o pacto de não agressão e o pacto que permite transformar o estado polêmico (de conflituosidade violenta) em estado agonístico (de conflituosidade não violenta), podem ser violados, e, portanto, também a proibição de recorrer à força recíproca, devendo valer também no caso em que um ou outro dos dois pactos anteriores, ou ambos, sejam eles próprios violados.

Isso significa que a proibição de recorrer à força deve valer não apenas para a solução dos conflitos primários, mas também para a solução do conflito secundário que pode nascer da inobservância das regras estabelecidas para a solução dos conflitos primários. ${ }^{60}$

Essa última condição requer a constituição de um poder comum, aquele poder que, segundo Hobbes e os contratualistas, permite a passagem do estado de natureza para o Estado civil. Um poder comum acima das partes requer a presença de um Terceiro, pressupõe portanto a passagem de uma situação de terceiro excluído para uma situação de terceiro incluído. ${ }^{61}$

Quando o Terceiro atua de modo insuficiente ou se encontra ausente ressurge o "velho sistema do equilíbrio, vale dizer, o sistema no qual a paz é garantida exclusivamente pelo medo recíproco" ${ }^{62}$. Se no passado a relação entre os sujeitos reais do sistema internacional era definida como equilíbrio das potências, hoje é definida como equilíbrio do terror, sendo que o que mudou foi apenas a potência das armas, que aumentou, mas não a razão do equilíbrio, que continua a ser o temor recíproco, característico, segundo a hipótese hobbesiana, do estado de natureza. ${ }^{63}$

\footnotetext{
$60 \quad$ Ibidem, p. 247.

61 BOBBIO, 2009.

62 Ibidem, p. 249.

63 Ibidem, p. 249.
} 
De fato, a ausência do Terceiro pode se dar, nos conflitos intraestatais, na verificação de que o Direito oficial - que apresenta um elevado grau de institucionalização da função jurídica, que se tornou especializada, autônoma, burocrática e sistematizada, apontando tarefas rigidamente definidas e hierarquizadas - já não é respeitado pelo cidadão. Talvez esse desrespeito ocorra porque as características do Direito anteriormente referidas trazem como consequências a padronização e a impessoalização de procedimentos, a falta de celeridade e, por último, a ineficácia na aplicação da lei em determinados litígios.

Entretanto, esse monopólio da força estatal vem se esfacelando. Isso significa que o Terceiro se ausenta porque o Estado, ente que reivindicava para si os meios de coerção oficiais de determinado território, agora encontra dificuldades de "ordenar", ou seja, de produzir ordem. ${ }^{64}$ Antes tal tarefa lhe era atribuída justamente porque para seu desempenho se faz necessário um aparelho burocrático hierárquico capaz de reunir e concentrar esforços. Cada vez mais se assiste à proliferação de direitos ditos extraoficiais que têm berço, quase sempre, na falta de atenção do Estado (nessa circunstância, um Terceiro ausente) para com os direitos fundamentais do cidadão.

Tal se dá porque todo conflito termina ou com a vitória de um dos dois rivais, ou então com a intervenção de um Terceiro (acima, no meio ou contra os rivais). Em outras palavras, se um conflito deve ser solucionado por meio da força, um dos dois deve ser eliminado. Para estabelecer o consenso na forma de um acordo duradouro o Terceiro muitas vezes desempenha o papel de aliado, neutro ou mediador de paz. Essa é a análise feita na sequência.

64 SPENGLER, 2017b. 


\subsection{O Terceiro aliado, o Terceiro neutro e o mediador}

\section{de paz}

Julien Freund, na obra Sociologia do conflito ${ }^{65}$, introduziu a distinção entre duas situações ideais típicas, a do "Terceiro excluído", atuante no "estado polêmico", e a do "Terceiro incluído", encontrado no "estado agonístico". Da análise feita por Freund ${ }^{66}$ é possível concluir que a sociedade interestatal de hoje ainda está essencialmente no estado polêmico, porém, a sociedade intraestatal encontra-se estabilizada, salvo situações específicas como revoluções, no estado agonístico. No primeiro caso, os conflitos são solucionados, ao fim e ao cabo, com a vitória de uma parte sobre a outra. No segundo, a presença de um Terceiro supra partes, que detém o monopólio da força legítima, permite soluções pactuadas e pacíficas dos principais conflitos internos, que, não solucionados, fariam o estado agonístico cair novamente no estado polêmico. ${ }^{67}$

Mas essa contraposição entre estado polêmico e estado agonal pode gerar a conclusão demasiado simplista das diferenças entre situação diádica e situação triádica. Isso acontece porque entre a ausência total do Terceiro e a presença do único Terceiro superior existem posições intermediárias que deram origem a estudos recentes. Tais estudos remontam uma vez mais a Simmel ${ }^{68}$, e trabalham com as várias figuras que o Terceiro pode assumir, entre a hipótese hobbesiana do estado polêmico originário, ou seja, da guerra de todos contra todos, e o estado agonístico final, não menos hipotético, da sociedade anárquica, sem Estado. ${ }^{69}$

\footnotetext{
65 FREUND, 1995a.

66 Ibidem.

67 BOBBIO, 2009, p.288.

68 SIMMEL, 1968.

69 BOBBIO, 2009, p. 288.
} 
Desse modo, para Bobbio ${ }^{70}$, que se baseia nas conclusões de Simmel ${ }^{71}$, a figura do Terceiro pode ser dividida quanto ao tipo de situação na qual se encontra inserido: polêmica ou agonal ${ }^{72}$.

Assim, quanto a situação polêmica:

a primeira figura é a do Aliado que se revela um Terceiro aparente porque é aquele que se enfileira ao lado de um ou outro dos contendores. Aparente porque enquanto não existirem outros terceiros além dos aliados, a situação permanece diádica.

Conforme Portinaro ${ }^{73}$, o aliado pode ser definido como amigo de um e inimigo do outro e que, por se tratar de um ator soberano, não pretende renunciar ao monopólio do político. Essa prerrogativa o expõe, porém, a necessidade de se posicionar com relação a dualidade amigo-inimigo dominante, perdendo, assim, sua autonomia no conjunto de atores principais de um conflito.

Freund $^{74}$ destaca que o aliado não é efetivamente um Terceiro justamente porque se coloca de um ou outro lado do conflito. Ao relacionar o Terceiro com a política, o autor afirma que essa última (política) e o jogo de relações de forças não se suprimem com uma "aliança", independentemente de se tratar de sindicatos, de estados ou inclusive de asso-

\section{$70 \quad$ Ibidem, p. 288-290.}

71 SIMMEL, 1968.

72 É importante referir que os sociólogos trabalhados na presente obra estabelecem classificações diferentes para o Terceiro e o papel por ele desempenhado. Porém, a maioria deles têm como fonte de inspiração a obra Sociologie de Simmel (1968) o que leva a crer que os pontos de divergência dizem respeito a interpretações individuais. Por isso, optou-se pela utilização da classificação exposta por Bobbio (2009), também baseada em Simmel.

73 PORTINARO, 1986.

74 FREUND, 1995a. 
ciações. A coligação jamais é perfeita, pois em uma aliança existe hierarquia, muitas vezes, inclusive, uma hegemonia entre os participantes.

Nesses termos, é o desenvolvimento do conflito propriamente que põe em xeque a coesão de uma aliança. Além disso, não se pode perder de vista que todas as alianças possuem, intrinsecamente, um caráter beligerante, uma vez que algumas são feitas para deflagrar a guerra e outras para negociar a paz. Nesse contexto, o Terceiro pode atuar exercendo o papel de proteção de um dos conflitantes.

na segunda hipótese encontra-se o verdadeiro Terceiro, o Neutro, que, não se enfileirando nem de um nem de outro lado, representa a passagem para uma situação que, embora continue sendo polêmica, não é mais apenas diádica. O Neutro é um Terceiro passivo, um Terceiro real, não interessado no conflito tal como o Aliado, porém ele é frágil.

Talvez essa fragilidade aconteça devido a um princípio que rege o mundo político e que determina "o con l' uno o con l'altro".$^{75}$ Nessa importante fórmula se condensa a necessidade de se posicionar, pressuposto elementar da afirmação de uma potência política.

Quanto à situação agonística:

a passagem para a situação agonística tem início com a primeira das várias formas de Terceiro ativo. Essa forma é do Mediador, aquele que se coloca entre as partes, não acima delas, para auxiliá-las a comunicar-se entre si, mas sem tomar os seus respectivos lugares na administração da controvérsia;

O Mediador é aquele que está "con l'uno e con l'altro"76. Trata-se de um terceiro real, autônomo na relação com os conflitantes. Ele se qualifica como o Terceiro forte se comparado ao Neutro e ao Aliado.

75 PORTINARO, op. cit., p. 21

76 PORTINARO, 1986, p. 18. 
continua com o Árbitro, ao qual as partes delegam a decisão, comprometendo-se a submeter-se a ele, e que, como tal, está, a um só tempo, entre e acima;

por fim se conclui com o Juiz, que está autorizado a intervir para solucionar o conflito, a partir de uma instância superior e é, portanto, a pleno direito, um Terceiro acima.

\section{Outras figuras de Terceiro}

Existem figuras de terceiro consideradas marginais. Essas figuras podem ser encontradas em ambos os estados e normalmente são agrupadas em duas categorias do Terceiro que, embora não sendo parte do conflito, tem alguma relação com ele:

Tertius gaudens: é aquele que tira vantagem do conflito. É assim denominado porque tira vantagem da controvérsia alheia, sem a ter provocado. A ele se aplica perfeitamente o ditado "enquanto dois brigam, o Terceiro aproveita", e também aquele conhecido como "semeador de discórdias", que coloca em prática o princípio divide et impera.

Essa é a figura daquele que agindo sorrateiramente induz os demais ao conflito e assim o age ou porque está impedido, por qualquer razão, de intervir abertamente ou porque simplesmente pensa ser possível obter, direta ou indiretamente, alguma vantagem. No primeiro caso esse Terceiro acabará por se descobrir, assim que possível, como o inimigo de um dos litigantes e, consequentemente, como Aliado do outro. No segundo caso, se tornará tão logo aquele conflito esteja estabilizado, o tertius gaudens da situação. $\mathrm{Na}$ medida em que ambas as figuras aparecem coligadas uma a outra, o semeador de discórdia e o tertius gaudens são duas manifestações, uma ativa e a outra passiva, do Terceiro fraudulento. ${ }^{77}$

77 Ibidem. 
O papel desempenhado pelo tertius gaudens envolve uma identidade particular, chamada de Terceiro emergente. Essa figura pode ser verificada no sistema internacional quando dominado pela bipolaridade e pelo antagonismo entre dois blocos. Ainda, tertius gaudens é uma figura recorrente dos sistemas nos quais a competição entre unidades soberanas pela divisão de recursos (fundamentalmente bens econômicos e ou valores estratégicos) se apresenta como uma competição bloqueada. Assim, ele pode ser definido como aquele ator que "intrattenendo scambi ineguali con entrambi i blocchi, massimiza il suo potere di negoziazione preservando la sua indipendenza". ${ }^{78}$

Tertius dolens é assim denominado aquele que sofre uma desvantagem da situação conflitiva. Esse é designado como "o bode expiatório", é aquele que se faz, ele próprio, de vítima, por incapacidade ou por vilania, é chamado o "servo de dois senhores". Se o tertius gaudens é aquele que pretende a obtenção de vantagens, o tertius dolens é quem paga a conta.

Essa é a figura do Terceiro que é feito (ou faz a si próprio?) de objeto de perseguição das partes envolvidas no conflito, sem que seu comportamento tenha dado motivo para o comportamento dos perseguidores. Devido a essa característica, o tertitus dolens é também chamado de "bode expiatório"79.

Até esse momento foi possível analisar a figurado Terceiro institucionalizado pelo Estado ou por órgãos supraestatais como a ONU. Porém, existem Terceiros que não necessariamente pertencem a instituições estatais e que exercem seu papel de equilíbrio e catálise. No entorno dessas figuras construiu-se o item adiante.

$78 \quad$ Ibidem, p. 221.

79 Ibidem, p.228. 


\subsection{O papel desenvolvido pelo Terceiro descentra- lizado/desinstitucionalizado}

Conforme se pôde verificar anteriormente, as figuras do Terceiro são várias; dependendo do contexto/situação/ estado no qual ele se encontra inserido, essa figura tem mais ou menos importância. É possível encontrar Terceiros em organizações, entidades, instituições estatais e não estatais, e muitos deles desempenham papel importante ao administrar conflitos.

Importante referir que a classe média é considerada, por Portinaro ${ }^{80}$, como um Terceiro no sentido de que se coloca entre classes extremas e garante, assim, certos limites, geradores de estabilidade social, freando a polarização e neutralizando o conflito entre o muito rico e o muito pobre. Porém, é interessante observar que a classe média ao desenvolver o papel de Terceiro poderá ser motivo de desintegração de um sistema econômico que se regia baseado no conflito das classes produtivas. Ainda, como aponta Portinaro, a classe média pode tornar-se um Terceiro privado de identidade, incapaz de ser um sujeito político unitário, dilacerado por conflitos corporativos, exigentes, para a gestão de tais conflitos, da presença de um Terceiro institucionalizado, supra-partes e por elas reconhecido. Nesse momento, o Estado voltaria a ser solicitado.

Muitas vezes o papel desempenhado por esses Terceiros tem como mola propulsora a crise de legitimidade estatal, que é consequência da crescente fragmentação e diversificação dos interesses sociais que resultam na agregação de tais interesses sob a forma de entidades (re)construídas. Portinaro $^{81}$ sugere que a perda da autoridade de Terceiro

80 PORTINARO, 1986.

81 Ibidem. 
por parte do Estado e das instituições a ele vinculadas é um sintoma preocupante. Justifica seu posicionamento afirmando que a sociedade atual encontra-se fragmentada e que a dissolução da identidade dos atores principais vem acompanhada pela perda de identidade dos sujeitos que deveriam desenvolver funções de mediação e coesão social. Assim, ao mesmo tempo que múltiplas identidades submetem ao Estado suas reivindicações, exigências e desafios da sociedade civil, nasce a crise de legitimidade representada justamente pela incapacidade estatal de atender simultaneamente essa ampla gama de exigências. Então, para superar sua própria deficiência, o Estado descentraliza parte de seus poderes em favor de instituições políticas locais e regionais. ${ }^{82}$

Essas instituições passam a atuar como Terceiros na administração dos conflitos a elas submetidos. Essa transferência decorre de duas tendências convergentes: de um lado, dada a "diferenciação territorial entre as duas instituições do Estado, as identidades das minorias regionais e nacionais conseguem se manifestar com maior desenvoltura em níveis local e regional". Por outro lado, observa-se que "os governos nacionais tendem a concentrar-se na administração dos desafios impostos pela globalização da riqueza, da comunicação, e do poder", sendo que a maior consequência dessa atitude é a permissão estatal para que os:

Escalões inferiores do governo assumam a responsabilidade pelas relações com a sociedade, tratando das questões do dia-a-dia, com o objetivo de reconstruir sua legitimidade por meio da descentralização do poder. ${ }^{83}$

82 CASTELLS, Manuel. O poder da identidade. A era da informação: economia, sociedade e cultura. Tradução de Klauss Brandini Gerhardt. 3 ed, São Paulo, Paz e Terra. 1999.

83 Ibidem, p.317. 
Portanto, a retração estatal e a abertura de espaços cada vez maiores fomenta o surgimento de entidades não-governamentais e autossuficientes (Terceiros) nascidas em comunidades locais para as quais o cidadão se volta buscando refúgio frente à incapacidade estatal. Assim, se o Estado cede/perde espaço, legitima a atuação dessas entidades (re)constuídas a partir de forças sociais ou políticas (que poderão ser religiosas, territoriais ou étnicas) e que podem assumir, em determinadas ocasiões, o controle estatal a fim de transformá-lo na sua expressão exclusiva. ${ }^{84}$ Então, verifica-se a existência de Estados esvaziados pela atuação desses Terceiros, que seguem lutando com todas as suas forças para reconstruir sua legitimação e instrumentalidade.

Essa pluralidade de ordens não legitimadas pelo Estado, com centros de poder muitas vezes extraoficiais, são poderes de fato cuja pretensão nem sempre é a oposição direta ao Estado. No entanto, alguns desses poderes são forças políticas que, consequentemente, se transformam em concorrentes diretos dos poderes oficialmente estabelecidos, pois, como eles, pretendem impor a sua concepção de direitos e de vida coletiva à comunidade como um todo. Dessa forma:

La vita degli stati vi è sempre stato un conflitto tra poteri di fatto e poteri costituiti. Ma nello stato democratico attuale, la novità è che vi è una certa legittimazione nell'attribuzione di questi poteri a ordinamento che però sono soltanto in maniera parziale riconosciuti come tali. ${ }^{85}$

84 Pode-se citar como exemplo, aqui, "o processo de formação dos Estados fundamentalistas (a República Islâmica do Irã, por exemplo), que num primeiro momento pode parecer uma injeção de ânimo no Estado-Nação, mas o que se vê, na verdade, é a mais aprofunda derrocada do EstadoNação, uma vez que o Islã não é, e nem pode ser, o Estado-Nação, mas sim a Umma, ou comunidade de fiéis". (CASTELLS, 1999, p. 321).

85 GERIN, Guido. La crisi dello Stato Democrático. Padova, CEDAM. 1974. 
Nesse contexto de crise e de deslegitimação estatal ainda que presente o risco da imposição de regras e condutas extraoficiais e carentes de legitimação por parte de instituições Terceiras -, é importante reconhecer que muitas vezes o papel desempenhado pelo Terceiro torna-se relevante devido a minimização da atuação estatal ou a sua efetiva ausência. Nesse momento conquistam legitimidade os sujeitos sociais que edificam uma nova cultura societária de base, cujos direitos insurgentes são a expressão mais autêntica da satisfação das carências e das necessidades humanas fundamentais. ${ }^{86}$

Então, é possível se deparar com novos atores sociais que desempenham papéis importantes e cujos critérios que compõem a sua legitimidade possuem alguns limites: nesse caso se está falando daquela legitimidade constituída a partir de um conteúdo de intenções programáticas, consideradas justas e que se articula não por quaisquer movimentos coletivos, e sim por aqueles comprometidos com as mudanças paradigmáticas ${ }^{87}$, com a pluralidade das formas de vida cotidiana e com o projeto de uma sociedade autogestionária, descentralizada, liberta e igualitária ${ }^{88}$. Consequentemente,

86 PORTINARO, 1986.

87 Sobre o assunto sugere-se a leitura de SPENGLER, Fabiana Marion; SPENGLER, Fernando Augusto Marion. Na Medicina e no Direito: como se rompe um paradigma? Revista Direitos Humanos e Democracia, v.6, p.98 - 115, 2018.

88 Com efeito, não é qualquer grupo social que gera "direitos" autênticos e torna-se essencial a distinção entre grupos comprometidos com as causas do "justo", do "ético" e do "bem comum" de grande parcela da comunidade e grupos sociais identificados com a manutenção dos privilégios, a dominação e a oposição a qualquer mudança (...). O conteúdo valorativo de uma manifestação normativa informalizada e não oficial é muito relativo, podendo ser moralmente correto ou não. A partir da análise da ética e da moral do grupo social, é possível verificar se temos um direito extra-oficial legítimo ou um direito marginal. (WOLKMER, 2001, p. 323-324). 
esses seriam os Terceiros considerados aos olhos estatais "não oficiais", mas legitimados por suas ações, suas práticas e pelo reconhecimento social delas advindo ${ }^{89}$.

Paralelamente, pode-se encontrar os movimentos/ grupos sociais não identificados com as ações civis e políticas justas e com os interesses do povo espoliado, marginalizado e oprimido, cuja legitimidade é questionada uma vez que:

Nem toda manifestação legal não-estatal ou nem todo 'direito' aí produzido pode ser justo, válido e ético" tal se dá porque um corpo social intermediário ou grupo dirigente qualquer pode "criar regras perversas", cujo objetivo é atender "interesses contrários à comunidade, expressando diretamente intentos de minorias identificadas com o poder, a dominação, a ambição, a exploração e o egoísmo. ${ }^{90}$

Assim, a ausência de ética e de bom senso esvaziam a legitimidade desses Terceiros, fazendo com que, em não raras as oportunidades, impere a lei do mais forte, ou seja, daquele que usa a violência para fazer valer o seu código e impor as suas regras. ${ }^{91}$

\section{Conclusão}

A pesquisa desenvolvida no presente texto demonstrou que a compreensão do papel do Terceiro na resolução/ administração dos conflitos depende, dentre outros fatores, da distinção entre as relações diádica e triádica e das situ-

89 Exemplo dessas organizações e desses direitos "não oficiais" são as comunidades organizadas para tratar seus conflitos utilizando-se, para isso dos projetos de justiça comunitária.

90 WOLKMER, Antônio Carlos. Pluralismo jurídico. Fundamentos de uma nova cultura no direito. 3 ed, São Paulo, Alfa Omega. 2001.

91 FARIA, J. E.; KUNTZ, R. Estado, sociedade e direito: qual o futuro dos direitos? Estado, mercado e justiça na reestruturação capitalista. São Paulo: Max Limonada, 2002. 
ações polêmica e agonal. Na situação polêmica diz-se que o Terceiro está excluído, o que resulta em violência aberta e direta. É uma situação conflitiva ou corre o risco de ser. Nesses casos os opositores se enfrentam, gerando violência física ou verbal.

Já na situação agonal, quando o Terceiro está incluído, encontram-se outras formas de rivalidade (a competição, por exemplo), assemelhando-se a um jogo. Nesse caso os rivais se comportam como adversários, excluindo-se a violência aberta. Além disso, na situação agonal, as regras são definidas de antemão e os meios para tal vão desde o estabelecimento de instituições até repercutir na criação do Direito, objetivando a submissão da vida à sua regulamentação.

Em resumo, tem-se que a situação polêmica exclui a figura do Terceiro e a situação agonal lida com uma relação de caráter triádico na qual a figura do Terceiro se encontra incluída.

Porém, avista-se a dificuldade de administrar e resolver os conflitos quando o Terceiro encontra-se ausente, permitindo o agravamento das manifestações conflitivas pela inexistência do seu poder de coação e do cumprimento dos acordos entabulados. Verifica-se, então, que no contexto intraestatal o Terceiro tem seu espaço e seu poder reconhecidos, o que não acontece com frequência nas relações intraestatais, nas quais o papel do Terceiro é, na maioria das vezes, exercido por organizações que não conseguem fazer cumprir os pactos convencionados.

Porém, o papel desempenhado pelo Terceiro pode ser reconhecido como amigo ou aliado de um dos envolvidos. Enquanto aliado de um dos conflitantes o Terceiro aqui chamado de "aparente" se dissolve no dualismo do "front". É aquele que se posiciona a favor de um ou outro conflitante perdendo sua qualidade de Terceiro em função da dinâmica de polarização que desenvolve. 
Já o Terceiro considerado "neutro" não está a favor de nenhuma das partes. Sua assistência torna possível a formação de uma estrutura tripolar relacional. Porém, o Terceiro neutro é o polo mais frágil da relação o que lhe rende o rótulo de "fraco". A exceção a essa regra, é o mediador de paz que, tratando-se de um Terceiro, autônomo com relação aos envolvidos no conflito, é chamado de "real" e cuja força vem de sua autoridade reconhecida qualificando-se, devido a ela, como Terceiro forte. Essa força é, de fato, pressuposto da sua capacidade de intervenção enquanto sujeito pacificador.

Diante de tais fatos é possível observar diferenças e similitudes entre as figuras do Terceiro expostas: o aliado (aparente), o neutral (fraco) e o mediador de paz (Terceiro forte). O primeiro se apresenta como uma figura parcial, que se posiciona entre as partes. Já os dois últimos são considerados imparciais. A imparcialidade se apresenta assim como um requisito de prudência necessário a quem deseja se aproximar dos conflitantes, na busca de uma estratégia que permita alcançar o acordo ou pronunciar um juízo de decisão sobre o conflito. Nas três figuras do Terceiro pode-se perceber que o sujeito "incluído" numa relação pertencente a situação agonal.

Por fim, o reconhecimento do papel desenvolvido pelo Terceiro descentralizado/desinstitucionalizado é o mais difícil pois com ele é necessário reconhecer também a crise de legitimidade estatal. Essa crise estatal traz consigo a fragmentação e a descentralização parcial de seus poderes em favor de instituições políticas locais e regionais. Por conseguinte, essas entidades não-governamentais e autossuficientes começam a atuar como Terceiros no conflitivo a elas submetidos. Porém, quando o papel desenvolvido por Terceiros não institucionalizados reflete falta de ética e de bom senso, atuando de modo contrário aos interesses dos 
conflitantes observa-se a hipótese de ausência, primeiramente do Estado e posteriormente do Terceiro descentralização e não institucionalizado, permitindo-se o risco de violência e da imposição da lei do mais forte.

Diante de tais fatos, constata-se que é importante e necessário reconhecer que o Terceiro possui o papel fundamental de triangularizar a relação e promover a resolução/ administração do conflito de maneira adequada, objetivando a restauração da convivência e a harmonização social. A adequação e a pertinência de sua ação apontam para o nível de evolução cultural, social e econômica dos envolvidos no conflito. Por isso, não obstante desenvolver um papel único e diferenciado a cada situação, é necessário reconhecer a importância e o papel desenvolvido pelo Terceiro reflete a sua absoluta necessidade na identificação, na administração e na resolução dos conflitos.

\section{REFERÊNCIAS}

ALMEIDA, Flávio Portela Lopes de. A teoria dos jogos: uma fundamentação teórica dos métodos de resolução de disputas. In: AZEVEDO, André Gomma de (Org.), Estudos em Arbitragem, Mediação e Negociação. v. 2, Brasília: Ed. Grupos de Pesquisa. pp.20-35, 2003.

BLANCHOT, Maurice. Pour l'amitié. Paris: Fourbis, 1996.

BOBBIO, Norberto. O Terceiro Ausente: Ensaios e Discursos sobre a Paz e a Guerra.Tradução de Daniela Versiani. Barueri: Manole, 2009.

BOURDIEU, Pierre. O Poder Simbólico. Tradução de Fernando Tomaz (português de Portugal). 9 ed, Rio de Janeiro: Bertrand Brasil, 2006. 
CASTELLS, Manuel. O poder da identidade. A era da informação: economia, sociedade e cultura. Tradução de Klauss Brandini Gerhardt. 3 ed, São Paulo: Paz e Terra, 1999.

COSI, Giovanni. Interessi, diritti, potere. Gestione dei conflitti e mediazione. In: ArsInterpretandi. n. 9. Padova: CEDAM, 2004.

DAHRENDORF, Ralf. O conflito social moderno. Um ensaio sobre a política da liberdade. Tradução de Renato Aguiar e Marco Antonio Esteves da Rocha. São Paulo: Jorge Zahar/ Edusp, 1992.

DICIO. Dicionário Online de Português. Significado de Terceiro. Disponível em http://www.dicio.com.br/terceiro/, acesso em 20/11/2019.

EINSTEIN, A.; FREUD, S. Um diálogo entre Freud e Einstein: por que a guerra?. Santa Maria: Fadisma, 2005.

ENRIQUEZ, Eugène. As figuras do poder. São Paulo:Via Lettera, 2007.

FARIA, J. E.; KUNTZ, R. Estado, sociedade e direito: qual o futuro dos direitos? Estado, mercado e justiça na reestruturação capitalista. São Paulo: Max Limonad, 2002.

FREUND, Julien. Sociología del conflicto. Traducción de Juan Guerrero Roiz de la Parra. Madrid, Ministerio de Defensa: Secretaría General Técnica. D. L, 1995a.

GARAPON, Antoine. Bem Julgar: ensaio sobre o ritual judiciário. Lisboa: Instituto Piaget, 1997.

GERIN, Guido. La crisi dello Stato Democrático. Padova: CEDAM, 1974.

GIRARD, René. La violenza e il sacro. Traduzione di Ottavio Fatica e Eva Czerkl. Milano: Adelphi, 2005. 
HAMPSHIRE, Stuart. Non c'è giustizia senza conflitto. Democrazia come confronto di idee. Traduzione di Giovanna Bettini. Milano: Feltrinelli, 2000.

MACHADO, Igor Suzano. A decisão judicial entre a hermenêutica moral e a articulação política. Revista Brasileira de Estudos Políticos. Belo Horizonte, n. 109, pp. 365-409, jul./ dez. 2014. MARX, Karl. Do capital. O rendimento e suas fontes. Tradução de Edgar Malagodi. São Paulo: Nova Cultural. (Os pensadores), 1996.

MOUFFE, Chantal. Por um modelo agonístico de democracia. In: Revista de Sociologia e Política, n. 25: p. 11-23, 2005. Disponível em http://www.redalyc.org/pdf/238/23802503. pdf, consultado em 20/11/2019. Revista de Sociologia e Política. 0104-4478.

NASAR, Sylvia. Uma mente Brilhante. Tradução de Sérgio Moraes Rego. Rio de Janeiro: Record, 2002.

PORTINARO, Píer Paolo. Il terzo. Una figura del Politico. Milano: Fraco Angeli, 1986.

SIMMEL, Georg. Soziologie. 5 ed, Berlim: Duncker \& Humblot, 1968.

SPENGLER, Fabiana Marion. Da jurisdição à mediação: por uma outra cultura no tratamento dos conflitos. 2 ed, Ijuí: Unijuí, 2016a.

. (Des)caminhos do Estado e da jurisdição [recurso eletrônico]. Santa Cruz do Sul: Essere nel Mondo, 2017a.

. O pluriverso conflitivo e seus reflexos na formação consensuada do Estado. In: Revista direitos fundamentais $\mathcal{E}$ democracia, 22, 3: p.189-209, 2017b. Disponível em http:// revistaeletronicardfd.unibrasil.com.br/index.php/rdfd/ issue/view/301982-0496, consultado em 20/11/19. Revista direitos fundamentais e democracia. 1982-0496. 
- Uma Relação a Três: O Papel Político e Sociológico do Terceiro no Tratamento dos Conflitos, 59: p. 553-583. Revista Dados (Rio de Janeiro), 2016b.

. Chi è dunque il Terzo? Riflessioni su società e conflitto.

Firenze: Classi, 2019.

.SPENGLER, Fernando Augusto Marion. Na Medicina e no Direito: como se rompe um paradigma? Revista Direitos Humanos e Democracia, v.6, p.98 - 115, 2018.

WALLACE, R. A.; WOLF, A. La teoria sociologica contemporanea. Traduzione di Daniela Sandri, Giovanni Dognini e Maurizio Pisati. Bologna: il Mulino, 2001.

WERMUTH, Maiquel Ângelo Dezordi. Porque a guerra? De Einstein e Freud à atualidade. Santa Cruz do Sul: Essere nel Mondo, 2015.

WOLKMER, Antônio Carlos. Pluralismo jurídico. Fundamentos de uma nova cultura no direito. 3 ed, São Paulo: Alfa Omega, 2001.

Recebido em 10/03/2019

Aprovado em 22/11/2019

Fabiana Marion Spengler

E-mail: fabiana@unisc.br 
